\title{
INTEGRATED WORK ENVIRONMENT FOR PEOPLE WITH DISABILITIES WITHIN THE CONTEXT OF THE BULGARIAN AND EUROPEAN LEGISLATION
}

\author{
Nikoleta LAZAROVA \\ "Neofit Rilski" South-West University, Blagoevgrad, Bulgaria \\ nikoletalazarova@abv.bg
}

\begin{abstract}
People with disabilities are one of the socially vulnerable groups in the labor market. The main reason for this negative trend is the lack of integrated work environment that creates conditions for equal exercise of their right to work. At national level, the main piece of legislation which governs the right of an integrated work environment is the Law on Integration of People with Disabilities. The integration of the work environment is crucial for ensuring the opportunity for employment and professional realization of people with disabilities. Namely the professional realization of the labor market is one of the main mechanisms for the overall integration of this social group in various spheres of public life, which is set as a priority objective in the UN Convention on the Rights of Persons with Disabilities.
\end{abstract}

Keywords: integrated work environment; people with disabilities; employment; socially vulnerable groups.

\section{Introduction}

People with disabilities are one of the socially vulnerable groups who face particular difficulties in their realiziation on the labor market. The reason for this problem is complex and results in a lack of integrated working environment, qualifications and/or professional experience, availability of social prejudices and discrimination in the exercise of labor rights of persons belonging to this group. As a result of these reasons, a large percentage of people with disabilities are permanently unemployed, which is becoming a major obstacle to their integration in various spheres of public life. Unemployment among the studied social group turned into an unfavorable trend that needs rethinking of this publicly significant problem and undertaking a series of legislative measures to resolve it.
2. Integrated work environment and its legal framework under Bulgarian and European legislation.

The legal regulation governing the integrated working environment is contained mainly in The Integration of Persons with Disabilities Act (IPDA), which governs the various mechanisms for the integration of persons of this social group [1]. The provision of Art. 4, para. 1 pt. 3 of IPDA states that one way for the integration of people with disabilities is providing employment and ensuring career opportunities as well as professional realization that could be implemented precisely by integrating of the working environment.

The integrated working environment as a concept finds its indirect application in the Labor Code (LC), which contains a number of special rules on work done by disabled workers. The purpose of these 
rules is to take account of the ill health of the worker or employee and to provide an opportunity to use their residual performance by performing suitable work under conditions that comply with their health condition. Special labor legal protection is realized by setting higher requirements for working conditions in respect of disabled persons as a socially vulnerable group. It is through this enhanced legal protection that there are aims to overcome the unequal treatment of this category of workers and employees who could not pursue work on equal terms with other workers or employees. The appropriate working conditions should be viewed as a whole, including all the working conditions in the exercise of a given working activity, which must necessarily conform to the amendments of the health condition of the relevant worker or employee. The scope of this concept should be included: the exercised employment function; integrated working environment; adapted working conditions at the workplace; safe and healthy working conditions. The problem that arises on the right to adequate conditions of disabled persons is rooted in the rules contained in the many regulations that are often at odds (The special protection of disabled persons, who are reassigned, is contained mainly in Chapter XV, Section III LC. In addition to the Labor Code, the legal framework concerning the suitable working conditions for disabled persons can be found in: Art. 16 para. 1, p. 3 and 4 HSWA; Chapter IV, Section III IPDA; Chapter II, Section I PADA; Ordinance on vocational rehabilitation). As a result of the lack of a coherent system, there are a number of difficulties in the interpretation and enforcement of the rules.

The adoption of the Integration of Persons with Disabilities Act is a logical continuation of the basic ideas set out in the Convention on the Rights of Persons with Disabilities, which was adopted and ratified by Bulgaria in 2012. The aim of the Convention is to promote, protect and ensure the full and equal enjoyment of rights and fundamental freedoms by persons with disabilities. With the provision of Art. 27 of the Convention there is recognized the right to work of people with disabilities on par with others, and this includes the right of an opportunity to earn a living by freely chosen or accepted work in the labor market and in a working environment that is open, non-discriminatory and accessible to people with disabilities. The States Parties undertake to ensure and promote the realization of the right to work, including for those who acquire a disability during the course of employment, by taking appropriate steps, including legislation, among which are: the prohibition of discrimination; enhanced protection of rights of persons with disabilities to just and favorable working conditions, including equal opportunities and equal pay for equal value of work; safe and healthy working conditions; enabling people with disabilities to have effective access to programs for technical and vocational guidance; creating employment opportunities and career advancement for persons with disabilities in the labor market; providing people with disabilities with reasonable accommodation in the workplace; cooperation for the acquisition of work experience in the open labor market by persons with disabilities, etc. A significant part of the regulation of the labor rights of people with disabilities in the Convention is aimed precisely to provide a satisfactory working environment by employers to help integrate this group into the labor market. 
3. Integrated working environment and adaption to the workplace as a means of realizing the employment of people with disabilities.

One of the reasons for people with disabilities to find poor realization in the labor market is the lack of integrated work environment that is tailored to their specific needs. $\S 1$, p. 12 of the Additional provisions of the IPDA contains a legal definition of the term "integrated work environment". According to the legal definition, what is integrated is this work environment that provides opportunities for people with disabilities and people without disabilities to work together. Based on the given definition, it is suggested that employers will need to adapt their usual working environment according to the functional capabilities of people with disabilities so that they are able to render service on par with other workers and employees. In this respect the provision of Art. 25 IPDA provides a number of measures to ensure the employment of people with disabilities in an integrated environment by introducing incentives for employers, resulting in financial assistance to adapt the working environment to the needs of the individual with a disability, equipment and job creation, tax incentives for improvements in the environment for the benefit of the worker and others. Despite the proposed legislative measures the problem with the employment of this social group continues to exist [2]. A small part of employers in the private sector take advantage of the relief provided for integrating the working environment. Employers prefer not to hire people with disabilities and for that reason they can find difficulties in terminating subsequently arisen employment relationships, as this category of workers and employees benefit from enhanced labor legal protection in case of termination pursuant to Art. 333, para. 1, p.
2 and p. 3 and para. 2 of the Labor Code (LC).

In connection with the integration of the working environment, with the provisions of art. 24 IPDA for the employer or appointing authority it is introduced an obligation to adapt the workplace to the needs of a disabled person the moment they are hired or when the disability occurs after they have been hired, except where costs are unjustifiably excessive and would seriously burden the employer. The provision of Art. 24 of the Integration of Persons with Disabilities Act is applicable only when the disability of the employee falls within the scope of $\S 1$, p. 1 of the Additional Provisions of the IPDA, according to which "disability" means any loss or distortion in the anatomical structure, physiology or in the psyche of an individual. There is no requirement that state to be established by an expert decision of the bodies of the medical expertise, which means that the presence of any damage, regardless of the degree of disability and its duration is a ground creating an obligation for the employer under Art. 24 IPDA.

The need to adapt the workplace exists whenever there is total or partial inability for the disabled person to be employed under existing conditions. The inability is strictly individual for each person and depends on a number of additional factors - type and degree of disability, available capacity, medical indicators for the restoration of health, etc. As already noted, the employer's obligation will arise regardless of the extent and duration of the settlement, but these factors will be important in determining the scope of actions on behalf of the employer related to the adjustment in the workplace.

It should be noted that in most cases not only the damage, but also the lack of appropriate conditions in the workplace create difficulty or inability of a person to 
participate fully in the labor process. The participation in the labor process should be understood not only working in an existing employment relationship, but also the possibility of setting up a new one. In many cases, people with disabilities are prevented from participating in tender procedures or other forms of verification of professional qualifications relevant to start a job due to lack of specific technologies or techniques to provide them with equal opportunities in constituting labor relations.

The main idea of the statutory obligation of the employer under Art. 24 IPDA is to adjust conditions in the workplace, so as not to give rise to the inability for people with disabilities to render their labor. Under $\S 1$, p. 11 of the Additional Provisions of IPDA, "the workplace" is a place, workshop room, machine room, installation and other territorial specific location in the enterprise or outside of it in telework, where the worker or employee instructed by the employer does their job in the performance of their duties under the employment relationship. Inability will be present in cases where the person with disabilities cannot perform their job at the designated for the purpose workplace and under the present conditions. The reasons that would prevent the person may be of a different nature, such as lack of: access to the workplace; appropriate software or other technological means necessary to carry out the relevant activity; healthy or safe work conditions corresponding to the functional status of the person. Adapting the workplace if any adverse elements are observed will be achieved by repairing or customizing them according to the individual needs of the person.

Despite its explicit legal regulation, the obligation of the employer to adjustment at work under Art. 24 IPDA is not unconditional. It will occur unless the cost of this adjustment is not unjustifiably excessive and would seriously burden the employer. This means that the employer has a subjective right to refuse to adapt the workplace in any case when they consider that they would suffer significant financial difficulties. Putting this legal framework is intended to settle a reasonable level of performance of the obligation under Art. 24, second sentence IPDA, but here arises a reasonable suspicion of possible abuse of rights by the employer. The assessment of the exercise of the right of refusal is made by the employer that should form it on the basis of various criteria such as cash required for customizing a job, time interval, human resources, etc. The criteria are not specifically defined, but they are placed depending on the specific needs of the individual and existing working conditions available to the employer. The right of refusal of the employer under Art. 24, second sentence IPDA may raise a number of legal disputes, particularly in the termination of employment relationships of persons with disabilities [3]. Pursuant to Art. 325, para. 1, p. 9 of the Labor Code, the employer is entitled to terminate the employment relationship of a worker or employee who cannot perform the assigned work due to illness resulting in permanent disability or medical contraindications based on the conclusion of the Labor Expert Medical Commission (LEMC). Termination in this case is inadmissible if the employer has another job that is appropriate for the health condition of the worker or employee and they are willing to take one. The question that arises is - is the employer obliged to adapt the old workplace, according to the health needs of a person if the enterprise does not have another appropriate job? Pursuant to Art. 24 IPDA, the employer will be obliged to adapt the workplace to the needs of a disabled person, unless the costs are unjustifiably excessive and would result in serious difficulty. As already 
stated, the assessment will be done by the employer, but it will be subject to judicial review. The court will find it difficult in such cases, since there is no explicit statutory criteria on which to determine whether the adjustment is within the frameworks of what is reasonable or it will actually lead to significant and unreasonable costs for the employer. In this connection, it is recommended that the legislature designate specific factors that the employer or other authorities should comply with when conducting assessment and verification of the right of refusal. Another issue which can occur is whether the termination of the employment contract under Art. 325, para. 1, p. 9 LC will be legitimate if the employer fails to perform their duty to adapt the workplace. The norm is contained in a special law and is designed to protect labor rights of workers or employees falling within the category of persons with disabilities, but substantially it is not attributable to the termination of the employment relationship on that basis. The ability or inability to adapt the workplace is not intended as a constituent element of Art. 325, paragraph 1, pt. 9 LC and is therefore not subject to discretion. In such a case, the argument for breach of Article 24 IPDA will be unfounded.

Another interesting hypothesis is that in which the employer refuses to employ a disabled person for a reason that will require adaptation in the workplace, which will both represent an unreasonably large expense for the employer. Can we assume that there is discrimination under Art. 12 of the Protection against Discrimination Act? I think the answer here should be negative in case the employer lawfully exercises the right of refusal pursuant to Art. 24, second sentence IPDA. It could not be assumed that the employer's conduct is discriminatory because it is not based on disability, but on significant financial costs necessary to adapt the workplace to the venue in person.

\section{Conclusion.}

Providing employment opportunities for people with disabilities should be one of the national priorities, both politically and socially. The realization on the labor market of this social group through an integrated work environment is one of the main ways of overcoming social isolation and fully integrating people with disabilities into society. On the one hand, the integrated work environment will enable persons of the group to participate fully in the labor process in terms consistent with their health needs. On the other hand, the ability to work in an integrated work environment will help to significantly increase the vocational training for people with disabilities. At present the, majority of this social group acquires their professional qualifications mainly in specialized enterprises and cooperatives or have trainings in a few specialized centers for teaching children with disabilities. Unfavorable in these cases is that the choice of profession is very limited and the qualification does not often match the dynamics of the labor market. It is necessary to raise employers' awareness on financial stimuli and incentives to ensure an integrated work environment that would allow a more permanent and qualitative employment for people with disabilities. In this connection, it is necessary to lay down clear and binding rules on the obligations of employers to adapt the working environment and to exercise greater control over their implementation. 
[1] Mihailov, G. , Ivanova, M. Регулаторна оценка за равенство в законотворчеството - In: Electronic Journal "Law, Politics, Administration, том 3, бp. 4, 2016, ISSN: 2367-4601, http://www.lpajournal.com/;

[2] Lazarova, V., Establishing work experience under the bulgarian legislation - In Electronic Jornal: Revista Europa des Este Unida, Numero 2, Julio/Diciembre, 2016, Chili, ISSN 0719-7284, http://www.europadelesteunida.com/;

[3] Lazarova, V., Видове искове по индивидуалните трудови спорове - В: сп. Търговско право, бр. 1, София, ИК „Труд и право“, 2006, ISSN: 1313-8133. 